\title{
Synthesis of porous Ni-Co-Mn oxide nanoneedles and the temperature dependence of their pseudocapacitive behavior
}

\author{
Guoping Xiong ${ }^{1,2 *}$, Pingge He $\mathrm{He}^{1,2,3}$, Lei Liu ${ }^{3}$, Tengfei Chen ${ }^{3}$ and Timothy S. Fisher ${ }^{1,2}$ \\ ${ }^{1}$ Birck Nanotechnology Center, Purdue University, West Lafayette, IN, USA, ${ }^{2}$ School of Mechanical Engineering, Purdue \\ University, West Lafayette, IN, USA, ${ }^{3}$ State Key Laboratory of Powder Metallurgy, Central South University, Changsha, China
}

OPEN ACCESS

Edited by:

Sihong Wang,

Stanford University, USA

Reviewed by:

Hongchang Pang,

Dalian University of Technology, China

Jie Wang,

Xi'an Jiaotong University, China

*Correspondence:

Guoping Xiong,

Birck Nanotechnology Center, School of Mechanical Engineering,

Purdue University,

1205 West State Street, West Lafayette, IN 47907-2057,

USA

xiongg@purdue.edu

Specialty section:

This article was submitted to

Nanoenergy Technologies and Materials, a section of the journal

Frontiers in Energy Research

Received: 22 July 2015

Accepted: 24 August 2015

Published: 07 September 2015

Citation:

Xiong G, He P, Liu L, Chen T and Fisher TS (2015) Synthesis of porous $\mathrm{Ni}-\mathrm{Co}-\mathrm{Mn}$ oxide nanoneedles and the temperature dependence of their pseudocapacitive behavior.

Front. Energy Res. 3:39. doi: 10.3389/fenrg.2015.00039
Porous $\mathrm{Ni}-\mathrm{Co}-\mathrm{Mn}$ oxide nanoneedles have been synthesized on $\mathrm{Ni}$ foam by a facile one-step hydrothermal method for use as supercapacitor electrodes. Structural and compositional characterizations indicate that $\mathrm{Ni}$, Co, and $\mathrm{Mn}$ elements are homogeneously distributed within the multi-component metal oxides. Such multi-component metal oxides with a homogenous structure exhibit high specific capacitance of $2023 \mathrm{~F} \mathrm{~g}^{-1}$ at $1 \mathrm{~mA} \mathrm{~cm}^{-2}$, high coulombic efficiencies (greater than 99\%), and good long-term cycle life (approximately $7 \%$ loss in specific capacitance over 3000 charge/discharge cycles) at room temperature $(\mathrm{RT})$. Moreover, the influence of temperature on the electrochemical performance of the electrodes has been characterized at temperatures ranging from 4 to $80^{\circ} \mathrm{C}$ in aqueous electrolytes. The thermal behavior of the electrodes reveals that elevated operating temperature promotes higher capacitance and lower internal resistance by increasing the ionic conductivity of the electrolyte and redox reaction rates at the interface of the electrodes and electrolytes. The capacitance of the electrodes increases by $84 \%$ at a nominal temperature of $80^{\circ} \mathrm{C}$ and decreases by $18 \%$ at $4{ }^{\circ} \mathrm{C}$, compared to that at RT. The overall set of results demonstrates that the new Ni-Co-Mn oxide nanoneedle electrodes are promising for high-performance pseudocapacitive electrodes with a wide usable temperature range.

Keywords: energy storage, pseudocapacitors, multi-component metal oxide, nanoneedles, thermal behavior, temperature influence

\section{Introduction}

The growing demand for mobile power in practical applications, such as electric vehicles and hybrid electric vehicles, has aroused much interest in developing advanced energy storage devices. Among these energy storage systems, supercapacitors have attracted extensive attention because of their higher power density than batteries, higher energy density than conventional electrolytic capacitors, and other advantages, such as long cycle life (Simon and Gogotsi, 2008; Xiong et al., 2014b). Designing new electrode materials with high surface area and electrical conductivity is crucial to enhance the energy and power densities of supercapacitors, and pseudocapacitive materials, such as transitional metal oxides, can significantly improve the energy densities compared to carbon-based electrode materials (Simon and Gogotsi, 2008; Huang et al., 2012; Xiong et al., 2013, 2014a). 
Among these, binary metal oxides, such as spinel nickel cobaltite $\left(\mathrm{NiCo}_{2} \mathrm{O}_{4}\right)$, have attracted particular interest recently because of their low-cost, abundant resources, and environmental benignity (Wei et al., 2010; Wu et al., 2014). More significantly, their superior electrical conductivity (at least two orders of magnitude higher) and higher electrochemical activity (more active redox states) than single-component metal oxides (e.g., nickel oxides and cobalt oxides) make them particularly suitable for a wide range of application conditions (Wei et al., 2010; Zou et al., 2013; Wu et al., 2014). $\mathrm{NiCo}_{2} \mathrm{O}_{4}$ with different morphologies, such as nanosheets, nanotubes, nanoneedles, and nanowires on different substrates (e.g., carbon cloth, Ni foam, and carbon nanofibers), have been extensively reported in literature (Yuan et al., 2012b; Zhang et al., 2012; Huang et al., 2013; Liu et al., 2013; Wang and Wang, 2013; Yu et al., 2013; Zhang and Lou, 2013a,b; Zou et al., 2013; Shen et al., 2014; Xu et al., 2014). In order to further increase the energy and power densities of the pseudocapacitive electrodes, single-component metal oxides combined with $\mathrm{NiCo}_{2} \mathrm{O}_{4}$ have been proposed in structural designs to increase redox activity (or the density of electroactive sites) (Liu et al., 2012; Yu et al., 2013). However, these attempts face several potential problems: (1) the multi-step fabrication procedures are complicated; (2) interfaces between the heterogeneous metal oxides may reduce electron transfer efficiency; and (3) full utilization of the electroactive sites of the mixed metal oxides is difficult to achieve. Therefore, a homogeneous multi-component ( $n \geq 3$, where $n$ is the number of the metal components) metal oxide with a homogeneous structure as an electrode material may be ideal to overcome the foregoing issues. To date, little prior work has considered multi-component metal oxide nanoneedle electrode materials for application as pseudocapacitive electrodes (Luo et al., 2008).

In addition, efficient thermal management of energy storage systems is crucial to their reliable performance over suitably wide temperature ranges. Stable electrochemical performance of supercapacitors over a wide range of temperatures is also essential to their applications in harsh environments and extreme conditions. Among the supercapacitor components, electrode materials can have a strong influence on the thermal performance of supercapacitors (Xiong et al., 2015b).

In this work, we report a cost-effective and facile approach to design and fabricate $\mathrm{Ni}-\mathrm{Co}-\mathrm{Mn}$ oxide nanoneedle arrays on $\mathrm{Ni}$ foam as a binder-free electrode for high-performance supercapacitors. The porous $\mathrm{Ni}-\mathrm{Co}-\mathrm{Mn}$ oxide nanoneedles with homogenous distributions of metal elements in a unitary/singular structure were prepared through a facile one-step hydrothermal process and subsequent annealing treatment in a steady $\mathrm{N}_{2}$ flow at $300^{\circ} \mathrm{C}$. Furthermore, for practical applications, thermal influence on electrochemical performance of the porous $\mathrm{Ni}-\mathrm{Co}-\mathrm{Mn}$ oxide nanoneedle electrodes in aqueous electrolytes has also been characterized over a temperature window ranging from 4 to $80^{\circ} \mathrm{C}$ in a three-electrode configuration.

\section{Materials and Methods}

\section{Material Syntheses}

All the reagents used in the experiment were of analytical grade and purchased from the Sigma-Aldrich. Ni foam
( $5 \mathrm{~mm} \times 14 \mathrm{~mm}$ in a rectangular shape) was immersed in a $3 \mathrm{M} \mathrm{HCl}$ solution for $5 \mathrm{~min}$ to get rid of the surface oxide layer. $1.455 \mathrm{~g} \mathrm{Co}\left(\mathrm{NO}_{3}\right)_{2} \cdot 6 \mathrm{H}_{2} \mathrm{O}, 1.45 \mathrm{~g} \mathrm{Ni}\left(\mathrm{NO}_{3}\right)_{2} \cdot 6 \mathrm{H}_{2} \mathrm{O}, 1.255 \mathrm{~g}$ $\mathrm{Mn}\left(\mathrm{NO}_{3}\right)_{2} \cdot 4 \mathrm{H}_{2} \mathrm{O}$, and $0.9 \mathrm{~g}$ urea were dissolved in $70 \mathrm{~mL}$ of DI water at room temperature (RT) to form a light pink solution. The solution with a volume of $14 \mathrm{~mL}$ was then transferred into a $20 \mathrm{~mL}$ Teflon-lined stainless steel autoclave. The autoclave was maintained at $135^{\circ} \mathrm{C}$ for $8 \mathrm{~h}$ in an electric oven and subsequently cooled down to RT in air. The samples were carefully washed many times and sonicated to remove the excessive metal oxides piled on the Ni ligament surface. To obtain the Ni-Co-Mn oxide, as-grown hydroxide precursor nanoneedle arrays were placed in a quartz tube furnace filled with a steady $\mathrm{N}_{2}$ flow and heating rate of $2^{\circ} \mathrm{C} / \mathrm{min}$, annealed at $300^{\circ} \mathrm{C}$ for $2 \mathrm{~h}$, and cooled to RT naturally in a steady $\mathrm{N}_{2}$ flow. For comparison, $\mathrm{NiCo}_{2} \mathrm{O}_{4}$ supported on $\mathrm{Ni}$ foam was also prepared under the same condition (Wang et al., 2013). To demonstrate the versatility of this synthesis process, $\mathrm{Ni}-\mathrm{Co}-\mathrm{Mn}$ oxide has also been synthesized on carbon cloth with the same reaction conditions. The mass of $\mathrm{Ni}-\mathrm{Co}-\mathrm{Mn}$ oxides was measured by the weight difference of $\mathrm{Ni}$ foam before and after the hydrothermal process and heat treatment using a microbalance with an accuracy of $1 \mu \mathrm{g}$.

\section{Material Characterization}

The morphology analyses were characterized with field emission scanning electron microscope (SEM, Hitachi S-4800) and a transmission electron microscopy (TEM, Japan FEM-2100F) combined with EDX mapping. The surface chemical composition was investigated by X-ray photoelectron spectroscopy (XPS, KAlpha 1063, UK Thermo Fisher) and the structure was analyzed by X-ray diffraction (XRD, D/max 2550) combined with the energy dispersive $\mathrm{X}$-ray spectroscopy (EDX) in TEM.

\section{Electrochemical Measurements}

Electrochemical measurements (Gamry Echem Testing System, Gamry Instruments, Inc., USA) were conducted in a threeelectrode configuration at RT using $2 \mathrm{M} \mathrm{KOH}$ as electrolyte. The nickel foam coated with electroactive materials serves directly as the working electrode. Pt mesh and standard calomel electrode (SCE) were used as the counter electrode and reference electrode, respectively. Electrochemical impedance spectroscopy (EIS) measurements were carried out with an amplitude of $5 \mathrm{mV}$ in the frequency ranging from $1 \mathrm{MHz}$ to $0.1 \mathrm{~Hz}$ at $0 \mathrm{~V}$. The specific capacitance of the electrodes is calculated from the charge/discharge curves based on Simon and Gogotsi (2008) and Xiong et al. (2014b):

$$
C_{m}=(I \times \Delta t) /(\Delta V \times m)
$$

where $C_{m}$ (Faraday per gram) is the specific capacitance, $I$ (ampere) is the current, $\Delta t$ (second) is the discharging time, $\Delta V$ (volt) is the potential drop during discharge, and $m$ (gram) is the mass of active materials.

In order to study the influence of temperature on the electrochemical performance of $\mathrm{Ni}-\mathrm{Co}-\mathrm{Mn}$ oxide electrodes, different operating temperatures of $4^{\circ} \mathrm{C}$, RT $\left(20^{\circ} \mathrm{C}\right), 40,60$, and $80^{\circ} \mathrm{C}$ have been chosen. SCE reference electrodes have a lower allowable temperature range. Also, $\mathrm{KOH}$ concentration was kept low $(0.1 \mathrm{M})$ because the $\mathrm{pH}$ would exceed the allowable range of the 
reference electrode. As a result of the two factors, $0.1 \mathrm{M} \mathrm{KOH}$ electrolyte and $\mathrm{Ag} / \mathrm{AgCl}$ reference electrodes are adopted during the electrochemical characterization of the electrodes at different temperatures.

\section{Results and Discussion}

Figures 1A,B contain scanning electron microscopy (SEM) images of the $\mathrm{Ni}-\mathrm{Co}-\mathrm{Mn}$ hydroxide precursor nanostructures on $\mathrm{Ni}$ foam. As shown in Figure $\mathbf{1 A}$, the $\mathrm{Ni}-\mathrm{Co}-\mathrm{Mn}$ precursor nanostructures grow uniformly on the substrate to form an array structure over a large area (see Figure 1A inset). These uniform nanostructures with needle-like shapes protrude roughly perpendicularly from the Ni foam ligaments (see Figure 1B). After annealing, the array structure and the nanoneedle shape are fully retained as shown in Figures 1C,D. The high-resolution SEM image in Figure 1D indicates that the nanoneedle tip diameters can be as small as a few nanometers. The morphologies of $\mathrm{NiCo}_{2} \mathrm{O}_{4}$ and $\mathrm{Ni}-\mathrm{Co}-\mathrm{Mn}$ oxides are compared in Figure $\mathrm{S} 1$ in Supplementary Material.

To demonstrate the versatility of this preparation process, $\mathrm{Ni}-\mathrm{Co}-\mathrm{Mn}$ oxide nanoneedle arrays have also been successfully grown on carbon cloth substrates using the same reaction conditions. $\mathrm{Ni}-\mathrm{Co}-\mathrm{Mn}$ oxide nanoneedles with sharp tips uniformly cover the surface of carbon fibers, similar to those grown on $\mathrm{Ni}$ foam (see Figure S2 in Supplementary Material).

These Ni-Co-Mn oxide nanoneedles have been further characterized by TEM as shown in Figure 2.

The needle-like $\mathrm{Ni}-\mathrm{Co}-\mathrm{Mn}$ oxide with tip diameters ranging from a few nanometers to several tens of nanometers can be clearly seen in Figure 2A, in agreement with the foregoing SEM results. Notably, the high-resolution TEM image in Figure 2B reveals a porous nature of nanoneedles. Such a porous structure is beneficial in facilitating electrolyte ion diffusion to the surface of electrodes for fast redox reactions and double-layer charge/discharge as well as increasing the electrode/electrolyte contact area, and consequently enhancing the electrochemical performance (Yuan et al., 2012a). The TEM elemental maps (see Figures 2B-F) confirm the homogenous distribution of $\mathrm{Ni}, \mathrm{Co}$, $\mathrm{Mn}$, and $\mathrm{O}$ elements in the unitary nanoneedle structure. The EDX data (see Figure S3 in Supplementary Material) also confirms the presence of the four elements in the nanoneedle structure. The contents of the metal components in the oxide prepared in this work are estimated from the EDX mapping and shown in Table $\mathrm{S} 1$ in Supplementary Material. The atomic ratio of Ni:Co:Mn in the as-prepared $\mathrm{Ni}-\mathrm{Co}-\mathrm{Mn}$ oxide nanoneedles is estimated to be $5: 5: 1$. However, they are tunable by adjusting the concentrations of raw chemicals in the precursor solution during the preparation process.

To characterize the structure and chemistry of these porous $\mathrm{Ni}-\mathrm{Co}-\mathrm{Mn}$ oxide nanoneedles, XRD and XPS were employed to analyze crystal structure and surface chemical composition. Figure 3A shows the wide-angle XRD pattern of the Ni-Co-Mn oxide nanoneedles grown on $\mathrm{Ni}$ foam. To reduce the effect of the $\mathrm{Ni}$ substrate, the $\mathrm{Ni}-\mathrm{Co}-\mathrm{Mn}$ oxide was scraped from the $\mathrm{Ni}$ foam for XRD characterization.

The XRD pattern of Ni-Co-Mn oxide nanoneedles and the standard XRD pattern of $\mathrm{NiCo}_{2} \mathrm{O}_{4}$ (indicated by the red lines) are shown in Figure 3A. Apart from the well-defined diffraction peaks observed at $2 \theta$ values of $18.9^{\circ}, 31.15^{\circ}, 36.6^{\circ}, 38.4^{\circ}, 44.6^{\circ}$, $55.4^{\circ}, 59.1^{\circ}, 64.9^{\circ}$, and $68.3^{\circ}$, which originate from the (111), (220), (311), (222), (400), (422), (511), (440), and (531) plane reflections

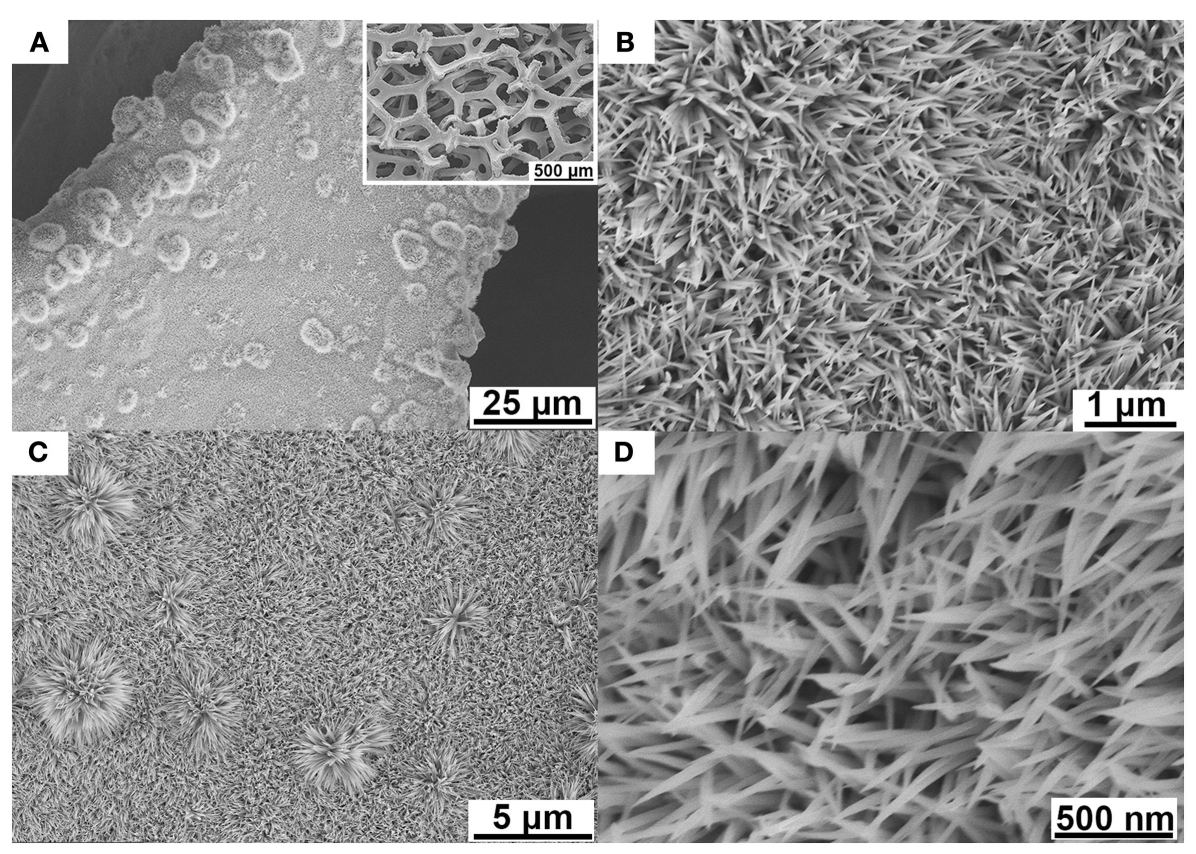

FIGURE 1 | SEM images (A) Ni-Co-Mn hydroxide nanoneedles grown on Ni foam, at low magnification (the inset shows the nanoneedles on Ni foam at a large scale). (B) Precursor hydroxide nanoneedles at higher magnification. (C) Ni-Co-Mn oxide on Ni foam after annealing. (D) High-resolution SEM image of $\mathrm{Ni}-\mathrm{Co}-\mathrm{Mn}$ oxide nanoneedles with ultra-sharp tips. 


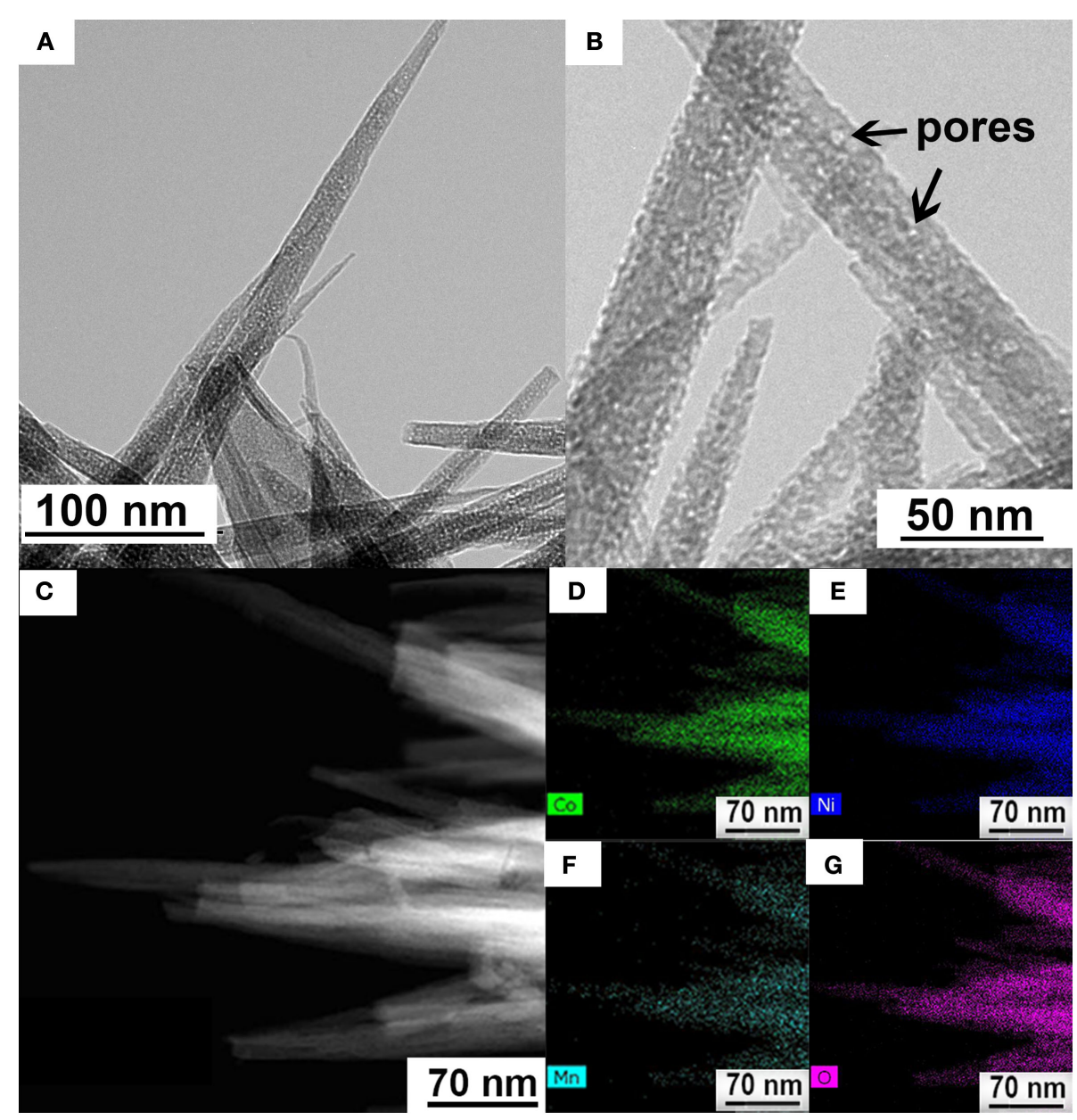

FIGURE 2 | (A) TEM image of Ni-Co-Mn oxide nanoneedles. (B) High-resolution TEM image showing the porous structure. (C) High-angle annular dark field (HAADF) scanning TEM image. (D-G) Elemental mapping showing uniform spatial distribution of mapped elements in the nanoneedles: (D-G) are Co, Ni, Mn, and O maps, respectively.

of the $\mathrm{NiCo}_{2} \mathrm{O}_{4}$ crystalline structure, the other two obvious peaks at $2 \theta$ values of $34.8^{\circ}$ and $58.5^{\circ}$ might be attributed to Mn effects, further confirming the presence of $\mathrm{Mn}$ in the structure. More detailed elemental composition (see Figure S4 in Supplementary Material) and oxidation states of as-prepared $\mathrm{Ni}-\mathrm{Co}-\mathrm{Mn}$ oxide are analyzed by XPS, and the corresponding results are displayed in Figures 3C,D. The Ni 2 p spectrum in Figure 3B is fitted by considering two spin-orbit doublets, characteristic of $\mathrm{Ni}^{2+}$ and $\mathrm{Ni}^{3+}$, and two shakeup satellites (identified as "Sat.") (Cui et al., 2009). Similarly, the Co 2 p spectrum (Figure 3C) is fitted with two spin-orbit doublets, characteristic of $\mathrm{Co}^{2+}$ and $\mathrm{Co}^{3+}$, and two shakeup satellites (Cui et al., 2009). In the Mn 2p spectrum (Figure 3D), the peaks observed at 641.5 and $653.2 \mathrm{eV}$ correspond to $\mathrm{Mn} 2 \mathrm{p}_{3 / 2}$ and $\mathrm{Mn} 2 \mathrm{p}_{1 / 2}$, respectively. However, distinguishing the binding energy corresponding to the oxidation states of $\mathrm{Mn}^{2+}$ and $\mathrm{Mn}^{3+}$ is difficult (Bag et al., 2014). Based on these analyses, the surface of as-prepared $\mathrm{Ni}-\mathrm{Co}-\mathrm{Mn}$ oxide possesses a composition containing $\mathrm{Ni}^{2+}, \mathrm{Ni}^{3+}, \mathrm{Co}^{2+}, \mathrm{Co}^{3+}, \mathrm{Mn}^{2+}$, and $\mathrm{Mn}^{3+}$.

Figure 4 provides characteristic electrochemical performance curves of the multi-component metal oxide. Figure 4A shows the cyclic voltammetry (CV) results of the $\mathrm{Ni}-\mathrm{Co}-\mathrm{Mn}$ oxide (a mass of approximately $0.11 \mathrm{mg}$, corresponding to a density of $0.5 \mathrm{mg} \mathrm{cm}^{-2}$ ) at voltage scan rates from 2 to $100 \mathrm{mV} \mathrm{s}^{-1}$ with a voltage window from -0.2 to $0.5 \mathrm{~V}$ vs. SCE in $2 \mathrm{M} \mathrm{KOH}$. Distinct redox peaks exist in the scanned $\mathrm{CV}$ curves at all scan rates, and these are primarily associated with faradaic redox reactions related to $\mathrm{M}-\mathrm{O} / \mathrm{M}-\mathrm{O}-\mathrm{OH}$ ( $\mathrm{M}$ represents $\mathrm{Ni}, \mathrm{Co}$, or $\mathrm{Mn}$ ) associated with $\mathrm{OH}^{-}$anions (Yuan et al., 2012a). The current response to the applied voltage sweep rate is shown in Figure S5 in Supplementary Material, in which the peak current is shown to be proportional to the scan rate, indicating that the redox reaction is controlled by surface adsorption (Simon et al., 2014). Similar peaks are also observed in CV curves of $\mathrm{NiCo}_{2} \mathrm{O}_{4}$ in a control experiment (see Figure S6A in Supplementary Material).

Figure 4B shows the galvanostatic charge/discharge profiles at different current densities ranging from 1 to $40 \mathrm{~mA} \mathrm{~cm}^{-2}$ (profiles at higher current densities are shown in Figure S7 in Supplementary Material), displaying a relatively symmetric shape. Voltage plateaus in discharge curves appear at around $0.2 \mathrm{~V}$, which is consistent with the CV curves of Figure 4A. Specific capacitances 

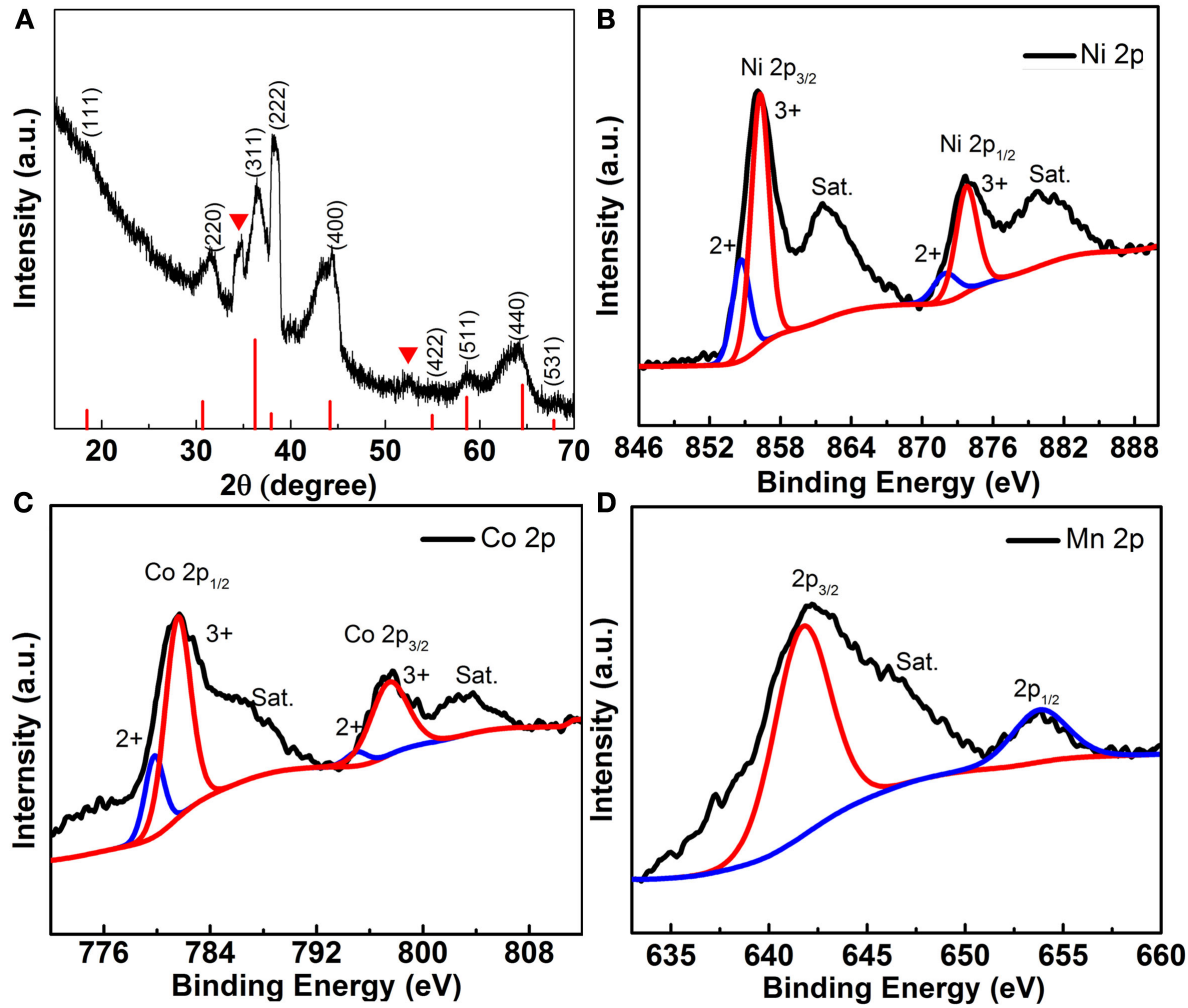

FIGURE 3 | (A) XRD pattern of Ni-Co-Mn oxide nanoneedles grown on Ni Foam. High-resolution XPS of (B) Ni 2p, (C) Co 2p, and (D) Mn 2p.
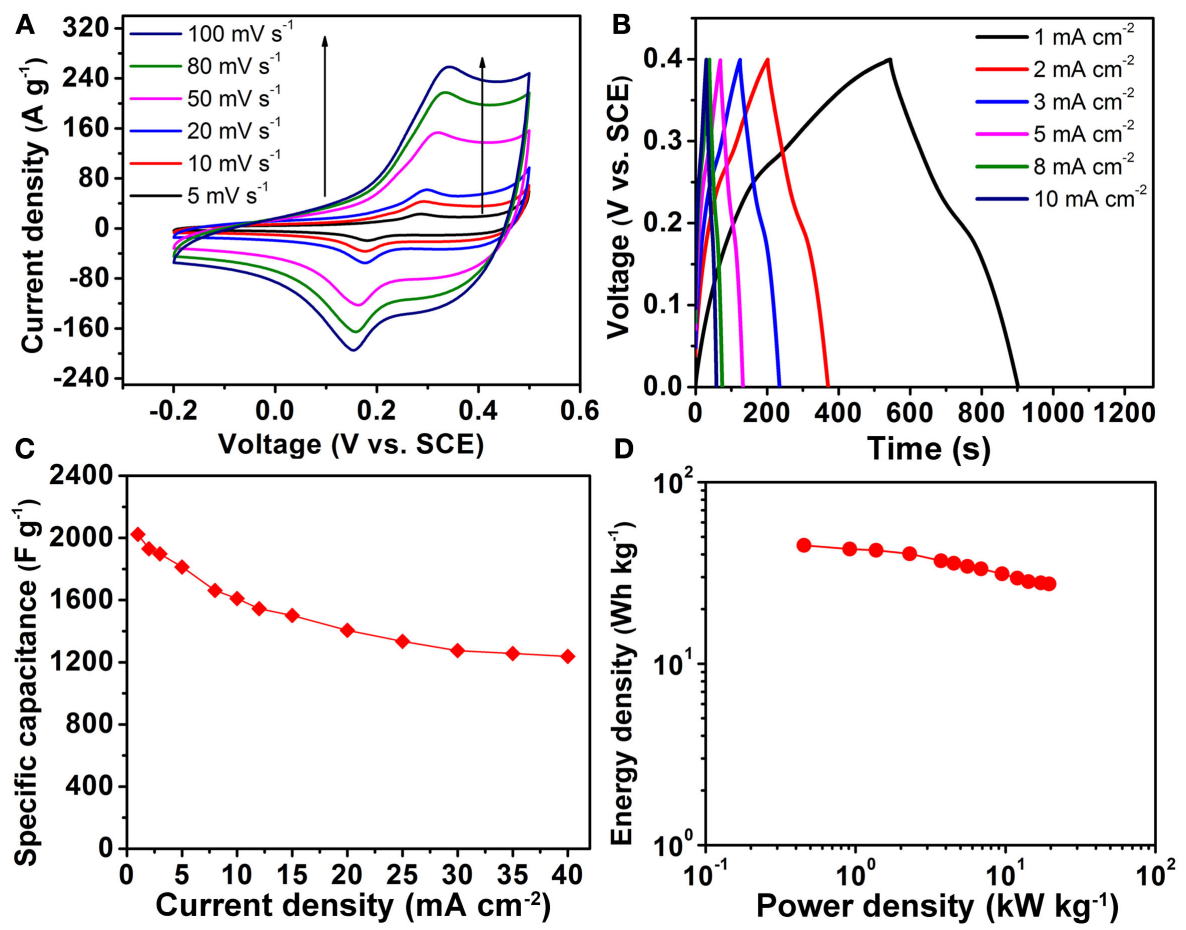

FIGURE 4 | (A) CV curves of Ni-Co-Mn oxide nanoneedle electrodes in $2 \mathrm{M} \mathrm{KOH}$ electrolyte from 5 to $100 \mathrm{mV} \mathrm{s}^{-1}$. (B) Galvanostatic charge/discharge curves of $\mathrm{Ni}-\mathrm{Co}-\mathrm{Mn}$ oxide electrodes at different current densities in the voltage range between 0 and $0.4 \mathrm{~V}$ vs. SCE. (C) Specific capacitance as a function of discharge current density. (D) Ragone plot of Ni-Co-Mn oxide nanoneedle electrodes. 
(using an active material mass basis) calculated by the method described in the Supplementary Material are plotted as a function of discharge current densities in Figure 4C. Notably, the specific capacitance of the $\mathrm{Ni}-\mathrm{Co}-\mathrm{Mn}$ oxide electrodes is greater than $2000 \mathrm{~F} \mathrm{~g}^{-1}$ at a discharge current density of $1 \mathrm{~mA} \mathrm{~cm}^{-2}$, which is more than three times higher than that of $\mathrm{NiCo}_{2} \mathrm{O}_{4}$ at the same current density (see Figure S6B in Supplementary Material). The significant enhancement in charge storage is also reflected in the comparative CV curves of the two oxide electrodes (see Figure S6A in Supplementary Material). This phenomenon of significantly enhanced specific capacitance of $\mathrm{Ni}-\mathrm{Co}-\mathrm{Mn}$ oxides compared to $\mathrm{NiCo}_{2} \mathrm{O}_{4}$ under the same growth condition was also observed on carbon cloth substrates (data not shown).

This significant increase in specific capacitance can be attributed to the unique homogeneous structure of the metal oxide with uniform distributions of $\mathrm{Ni}, \mathrm{Co}$, and $\mathrm{Mn}$ elements, increased number of oxidation states and synergistic effects of the ternary metal components in the electrodes. The specific capacitance of the multi-component metal oxide drops to $\sim 1250 \mathrm{~F} \mathrm{~g}^{-1}$ at a high current density of $40 \mathrm{~mA} \mathrm{~cm}^{-2}$ (corresponding to $\sim 80 \mathrm{~A} \mathrm{~g}^{-1}$ ), indicating a fairly good rate capability. Figure 4D shows the Ragone plot for the $\mathrm{Ni}-\mathrm{Co}-\mathrm{Mn}$ oxide electrode at different current densities. The energy density decreases from 45 to $27.5 \mathrm{Wh} \mathrm{kg}^{-1}$, while the average power density increases from 0.9 to $19.5 \mathrm{~kW} \mathrm{~kg}^{-1}$ as the galvanostatic charge/discharge current increases from 1 to $40 \mathrm{~mA} \mathrm{~cm}{ }^{-2}$. These values are more promising than the reported energy and power densities of $\mathrm{NiCo}_{2} \mathrm{O}_{4}$ nanowires (energy and power densities less than $20 \mathrm{Wh} \mathrm{kg}^{-1}$ and $7 \mathrm{~kW} \mathrm{~kg}^{-1}$, respectively) (Jiang et al., 2012), suggesting that the $\mathrm{Ni}-\mathrm{Co}-\mathrm{Mn}$ oxide electrode warrants further development as an electrode material in supercapacitor applications.

Figure 5A shows the Nyquist plot for the $\mathrm{Ni}-\mathrm{Co}-\mathrm{Mn}$ oxide nanoneedle electrodes recorded from $0.1 \mathrm{~Hz}$ to $1 \mathrm{MHz}$. The equivalent series resistance (ESR) value calculated from Figure 5A for the $\mathrm{Ni}-\mathrm{Co}-\mathrm{Mn}$ oxide electrodes is as low as $1.29 \Omega$. Notably, the Nyquist plot shows no characteristic circular curvature in the high frequency region, indicating that the charge transfer resistance in the electrodes during charge/discharge process is negligible, which suggests very low electrical resistivity of the material and high charge transfer efficiency at the interface of the $\mathrm{Ni}-\mathrm{Co}-\mathrm{Mn}$ oxide electrodes. Moreover, the linear behavior in the low frequency range is indicative of capacitive behavior of the electrodes.

Long-term cycle life is one of the most critical issues concerning metal oxide-based supercapacitor electrodes. Figure 5B shows the specific capacitance retention as a function of cycle number. The multi-component metal oxide electrode shows $\sim 7 \%$ loss in specific capacitance over 3000 charge/discharge cycles at a current density of $10 \mathrm{~mA} \mathrm{~cm}^{-2}$ and high coulombic efficiencies (>99\%), indicating good long-term cyclic stability and high charge storage/utilization efficiencies. No noticeable changes in the morphology of the nanoneedle electrodes were observed
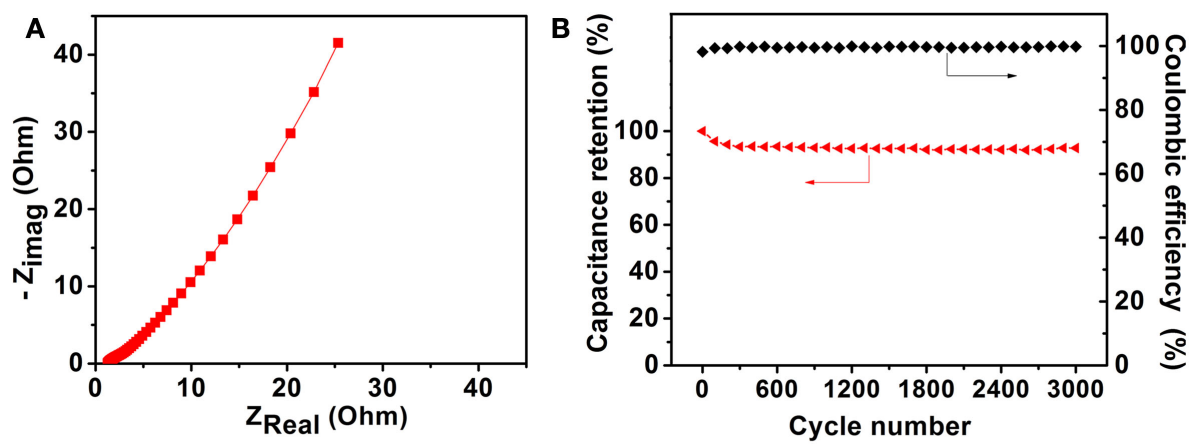

Specific capacitance $(\times 1000) @ 1$ mA cm-2

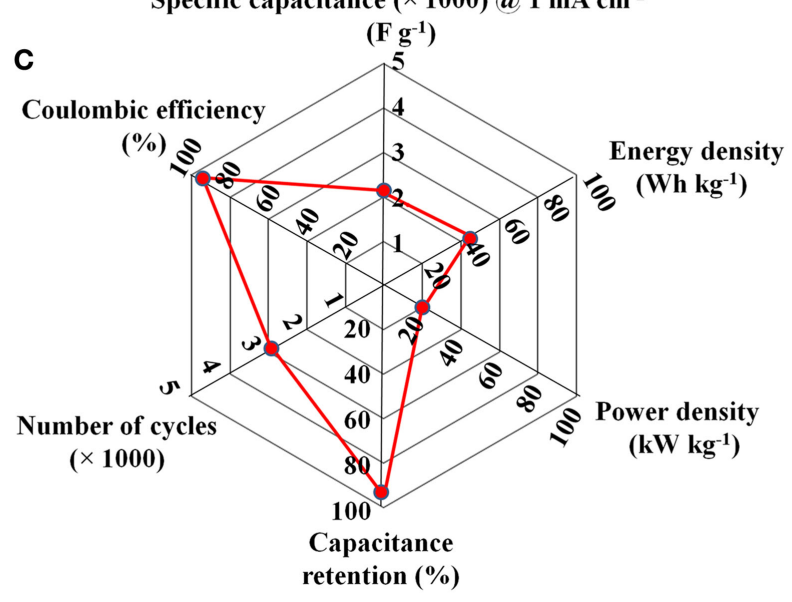

FIGURE 5 | (A) Nyquist plot for the Ni-Co-Mn oxide nanoneedle electrodes recorded from $0.1 \mathrm{~Hz}$ to $1 \mathrm{MHz}$. (B) Charge/discharge cycling stability test at a current density of $10 \mathrm{~mA} \mathrm{~cm}^{-2}$ and coulombic efficiencies during the test. (C) A radar plot to summarize the electrochemical performance of the Ni-Co-Mn oxide nanoneedle electrodes. 
after the long-term cycling tests (see Figure S8 in Supplementary Material). The excellent stability is likely attributable to the uniform structure and the robust mechanical contact between the nanoneedles and substrate. A radar plot to summarize the overall electrochemical performance of the $\mathrm{Ni}-\mathrm{Co}-\mathrm{Mn}$ oxide nanoneedle electrodes is provided in Figure 5C.

Thermal influence on the electrochemical performance of $\mathrm{Ni}-\mathrm{Co}-\mathrm{Mn}$ oxide electrodes has been studied by electrochemically characterizing the electrodes in $0.1 \mathrm{M} \mathrm{KOH}$ electrolyte with $\mathrm{Ag} / \mathrm{AgCl}$ as a reference electrode. The trend of temperature influence on electrochemical performance of the $\mathrm{Ni}-\mathrm{Co}-\mathrm{Mn}$ oxide nanoneedles in $2 \mathrm{M} \mathrm{KOH}$ is expected to be similar to that in $0.1 \mathrm{M}$ $\mathrm{KOH}$. Figure 6 shows the electrochemical performance of the as-prepared multi-component metal oxide electrodes at different temperatures of $4^{\circ} \mathrm{C}, \mathrm{RT}, 40,60$, and $80^{\circ} \mathrm{C}$. Figure $6 \mathrm{~A}$ shows the $\mathrm{CV}$ curves of $\mathrm{Ni}-\mathrm{Co}-\mathrm{Mn}$ oxide nanoneedle electrodes at a fixed scan rate of $10 \mathrm{mV} \mathrm{s}^{-1}$. The area of $\mathrm{CV}$ loop of the metal oxide electrodes gradually increases with operating temperature, indicating an increase in the capacitance with increasing temperature. At a temperature of $4^{\circ} \mathrm{C}$, the area of the $\mathrm{CV}$ loop is significantly smaller than that at $80^{\circ} \mathrm{C}$, indicating that temperature influences capacitance of the multi-component metal oxide significantly within a relatively wide temperature range for aqueous electrolytes.

The redox peak in Figure $\mathbf{6 A}$ (located around $0.3 \mathrm{~V}$ vs. $\mathrm{Ag} / \mathrm{AgCl}$ ) corresponding to the pseudocapacitance from the reversible electrochemical reaction between the metal oxide electrodes and electrolyte becomes more prominent at elevated temperatures as compared to low temperatures. Bo et al. proposed that mechanisms including liquid flow/mass transport in nanoscale regions, charge storage at the interface of electrolyte and electrode materials, and electron transport affect the electrochemical behavior of supercapacitors (Bo et al., 2015). Higher operating temperature facilitates higher ionic conductivity of electrolytes, and enhanced flow/mass transport at the interface of metal oxide/aqueous electrolytes and electron transport in the electrode material, leading to significant differences in charge storage at different temperatures.

Figure 6B displays the galvanostatic charge/discharge curves of $\mathrm{Ni}-\mathrm{Co}-\mathrm{Mn}$ oxide electrodes at a current density of $1 \mathrm{~mA} \mathrm{~cm}^{-2}$ and different temperatures of $4^{\circ} \mathrm{C}, \mathrm{RT}, 40,60$, and $80^{\circ} \mathrm{C}$ in the voltage range between 0 and $0.4 \mathrm{~V}$ vs. $\mathrm{Ag} / \mathrm{AgCl}$. The charge/discharge curves of the metal oxide electrodes are relatively symmetric at all temperatures studied. The time period required for the electrode to charge to $0.4 \mathrm{~V}$ or discharge to $0 \mathrm{~V}$ increases with operating temperature. In contrast, the initial potential drop associated with the cell internal resistance (known as IR drop) in the discharge curves decreases with increasing operating temperature (see Figure S9 in Supplementary Material), indicating a decreasing IR at elevated temperatures.

Figure 6C shows the areal capacitances of $\mathrm{Ni}-\mathrm{Co}-\mathrm{Mn}$ oxide electrodes at different operating temperatures calculated from
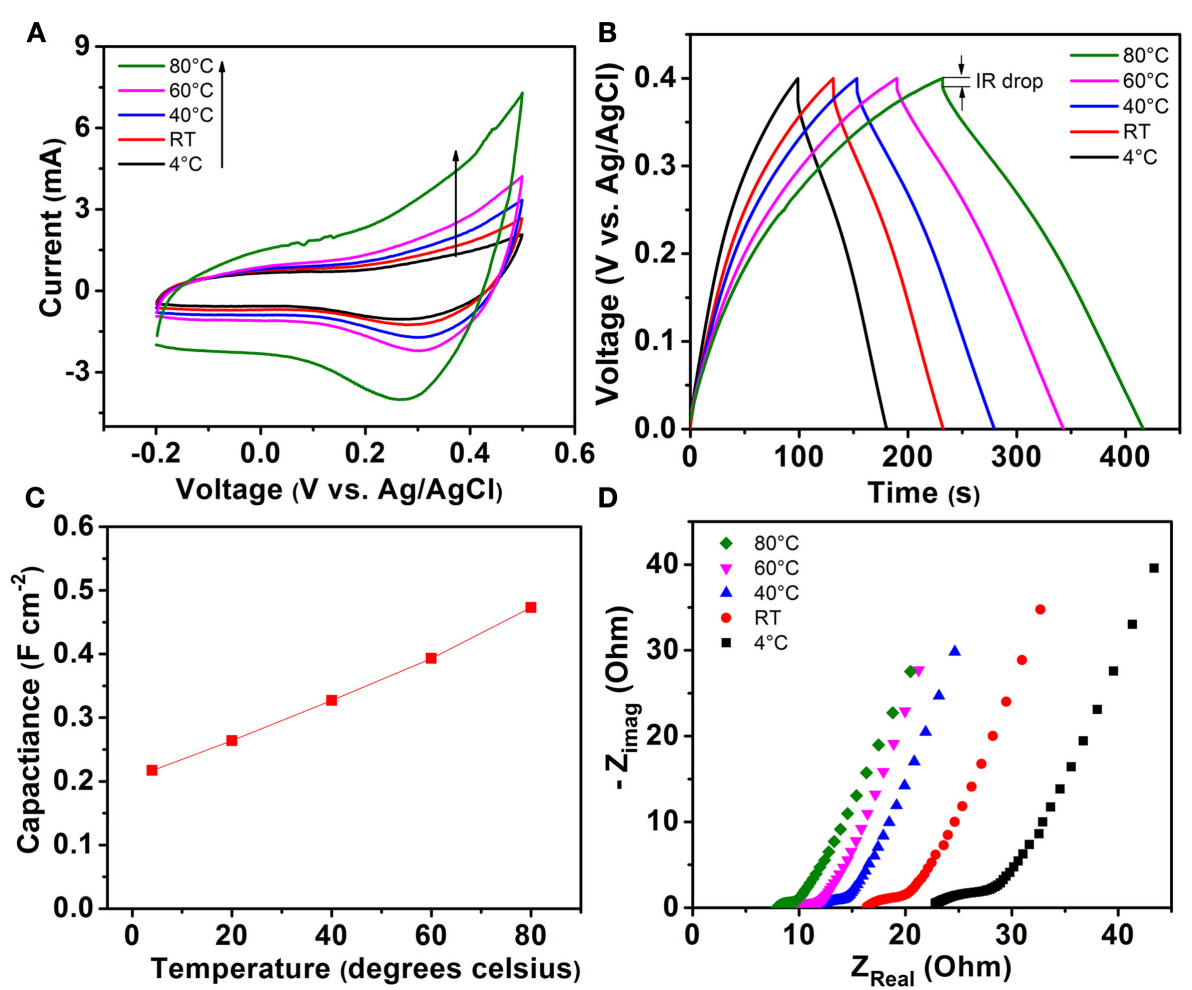

FIGURE 6 | (A) CV curves of $\mathrm{Ni}-\mathrm{Co}-\mathrm{Mn}$ oxide nanoneedle electrodes at a fixed scan rate of $10 \mathrm{mV} \mathrm{s}^{-1}$ in $0.1 \mathrm{M} \mathrm{KOH}$ electrolyte at temperatures of $4^{\circ} \mathrm{C}$, $\mathrm{RT}$, 40 , 60 , and $80^{\circ} \mathrm{C}$. (B) Galvanostatic charge/discharge curves of Ni-Co-Mn oxide electrodes at a current density of $1 \mathrm{~mA} \mathrm{~cm}^{-2}$ and temperatures of $4^{\circ} \mathrm{C}, \mathrm{RT}, 40,60$, and $80^{\circ} \mathrm{C}$ in the voltage range between 0 and $0.4 \mathrm{~V} \mathrm{vs.} \mathrm{Ag} / \mathrm{AgCl}$. (C) Areal capacitances of metal oxide electrodes calculated from charge/discharge curves in (B) at different temperatures at a constant current density of $1 \mathrm{~mA} \mathrm{~cm}^{-2}$. (D) Nyquist plot for the Ni-Co-Mn oxide nanoneedle electrodes recorded from $0.1 \mathrm{~Hz}$ to $1 \mathrm{MHz}$ measured at different temperatures. 
the galvanostatic charge/discharge curves in Figure 6B using the method described in the Supplementary Material. At RT, $\mathrm{Ni}-\mathrm{Co}-\mathrm{Mn}$ oxide electrodes exhibit a capacitance of $\sim 0.26 \mathrm{~F} \mathrm{~cm}^{-2}$ at a current density of $1 \mathrm{~mA} \mathrm{~cm}^{-2}$. When temperature increases to $80^{\circ} \mathrm{C}$, the capacitance reaches $0.48 \mathrm{~F} \mathrm{~cm}^{-2}$ or $84 \%$ higher than that at RT. This large increase in capacitance is significantly higher than that reported for other electrodes in aqueous electrolytes. Moreover, at a temperature of $4^{\circ} \mathrm{C}$, the capacitance decreases by $18 \%$ compared to that at RT. These large variations of capacitance induced by temperature change are comparable to or larger than other reported values in prior work (Zheng and Jow, 1996; Kotz et al., 2006; Liu and Pickup, 2008; Xiong et al., 2015a). These results suggest that temperature influences the electrochemical performance of $\mathrm{Ni}-\mathrm{Co}-\mathrm{Mn}$ oxide nanoneedles more by affecting the ion transport behavior and faradaic reactions at the interface between the electrode and electrolyte.

Interactions between electrodes and electrolytes at high/low temperatures may affect the subsequent performance at RT (e.g., cycling to/from high or low temperatures) (Xiong et al., 2015b). The thermal stability and repeatability of the $\mathrm{Ni}-\mathrm{Co}-\mathrm{Mn}$ oxide electrodes has also been demonstrated by characterizing them at RT, after being tested at $80^{\circ} \mathrm{C}$ (see Figure S10 in Supplementary Material). Figure S10 in Supplementary Material compares the CV curves measured at RT before and after an excursion to high temperature, and the discharge curves of the two results almost overlap, indicating excellent stability and repeatability of the electrodes within in a wide range of temperatures. These results differ from prior observations in which chemical changes occurred between carbon electrodes and organic electrolytes caused by reversible/irreversible redox reactions (possible surface modification of the electrode surface) (Masarapu et al., 2009).

Comparative Nyquist plots for the $\mathrm{Ni}-\mathrm{Co}-\mathrm{Mn}$ oxide nanoneedle electrodes recorded from $0.1 \mathrm{~Hz}$ to $1 \mathrm{MHz}$ at different temperatures are shown in Figure 6D. The measured impedance spectrum can be fitted by an equivalent circuit (Conway, 2013), consisting of a bulk electrolyte resistance, a charge transfer resistance, a pseudocapacitive element from redox reactions of the electrode materials and electrolyte, and a constant phase element (CPE) to represent the double-layer capacitance. The bulk electrolyte resistance is reflected by the real-axis intercept of the impedance spectrum at high frequency. As shown in Figure 6D, the bulk resistance of aqueous electrolyte decreases from 22.8 to $7.9 \Omega$ as operating temperature increases from 4 to $80^{\circ} \mathrm{C}$. This nearly threefold decrease in bulk resistance of electrolytes indicates that temperature influences ionic conductivity of the electrolytes substantially over a wide range of operating temperatures. At higher temperatures, the ionic conductivity of aqueous electrolytes is higher than that at lower temperatures. A similar phenomenon has also been reported (See and White, 1997).

Compared to RT, the resistance at $80^{\circ} \mathrm{C}$ is decreased by $50 \%$, which is comparable to other reports based on aqueous electrolytes in prior work (Liu and Pickup, 2008). Charge transfer resistance reflects the faradaic reaction rate and ion transfer kinetics at the interface between active metal oxides and electrolytes. A higher charge transfer resistance indicates a lower redox reaction rate. Significantly, Figure 6D indicates that charge transfer resistance increases as operating temperature decreases. At an operating temperature of $4^{\circ} \mathrm{C}$, the charge transfer resistance is estimated to be $8.2 \Omega$, which is much higher than that at $80^{\circ} \mathrm{C}(2.2 \Omega)$. This result indicates that operating temperature significantly affects the charge transfer kinetics and faradaic reaction rate at the interface between electrolyte and $\mathrm{Ni}-\mathrm{Co}-\mathrm{Mn}$ oxide nanoneedles, which largely explains the phenomenon of the higher capacitance at higher operating temperatures (see Figure 6C).

The kinetics of ionic transport involved in the process can be expressed by an Arrhenius-type equation: $C=C_{0} \exp (-Q / R T)$, where $C$ is the amount of charge accumulated at the electrode-electrolyte interfacial zone enabled by the molecular or ionic motion mechanism, $C_{0}$ is a pre-exponential constant, $Q$ is the activation energy, $T$ is absolute temperature, and $R$ is the universal gas constant (Liu et al., 2010). The Arrhenius plot of specific capacitance as a function of inverse temperature for the kinetics of ionic transport for the $\mathrm{Ni}-\mathrm{Co}-\mathrm{Mn}$ oxide electrode in aqueous electrolyte is plotted in Figure S11 in Supplementary Material, in which a linear relationship between $\ln (C)$ and $1 / T$ is observed with a fixed slope $-Q / R$. Consequently, the activation energy $Q$ derived from the Arrhenius equation is calculated to be $8.27 \mathrm{~kJ} \mathrm{~mol}^{-1}$.

\section{Conclusion}

In conclusion, a facile and cost-effective strategy has been developed to design and synthesize a multi-component $\mathrm{Ni}-\mathrm{Co}-\mathrm{Mn}$ oxide with a homogenous structure for high-performance supercapacitor electrode applications. The multi-component metal oxide electrode exhibits a specific capacitance of $2023 \mathrm{Fg}^{-1}$ at $1 \mathrm{~mA} \mathrm{~cm}^{-2}$, three times higher than that of $\mathrm{NiCo}_{2} \mathrm{O}_{4}$ in the control experiments, excellent long-term stability, and low IR. Such intriguing pesudocapacitive behavior is attributed to the unique homogeneous structure of the metal oxide with uniform distributions of $\mathrm{Ni}, \mathrm{Co}$, and $\mathrm{Mn}$ elements, enhanced oxidation states, and synergistic effects of the multi-metal components in the electrodes. This enhancement can be further maximized by adjusting the ratios of these elements in the oxides in the future. Moreover, the influence of temperature on $\mathrm{Ni}-\mathrm{Co}-\mathrm{Mn}$ oxide electrodes in a three-electrode configuration in aqueous electrolyte has been studied over a relatively wide temperature range. Temperature affects the capacitance and IR significantly by altering the ionic conductivity of electrolytes and faradaic reaction rates at the electrode surface. The multi-component electrode in this study exhibits excellent thermal stability and repeatability within this wide temperature range. This work opens new pathways to design electrode materials with enhanced electroactive sites for pesudocapacitive reactions and wide usable temperature ranges, and thus further boosts the energy and power densities of pseudocapacitive electrodes to become more competitive with traditional batteries.

\section{Acknowledgments}

The authors gratefully acknowledge support from the US Air Force Office of Scientific Research under the MURI Program on Nanofabrication of Tunable 3D Nanotube Architectures (PM: Dr. Joycelyn Harrison, Grant: FA9550-12-1-0037), 
the US National Science Foundation's Scalable Nanomanufacturing Program (Grant: 1344654), and the National High-Tech Research and Development Program of China (863 Program) No. 2012AA03A207.

\section{References}

Bag, S., Roy, K., Gopinath, C. S., and Raj, C. R. (2014). Facile single-step synthesis of nitrogen-doped reduced graphene oxide- $\mathrm{Mn} 3 \mathrm{O} 4$ hybrid functional material for the electrocatalytic reduction of oxygen. ACS Appl. Mater. Interfaces 6, 2692-2699. doi:10.1021/am405213z

Bo, Z., Mao, S., Han, Z. J., Cen, K., Chen, J., and Ostrikov, K. K. (2015). Emerging energy and environmental applications of vertically-oriented graphenes. Chem. Soc. Rev. 44, 2108-2121. doi:10.1039/c4cs00352g

Conway, B. E. (2013). Electrochemical Supercapacitors: Scientific Fundamentals and Technological Applications. New York: Springer Science \& Business Media.

Cui, B., Lin, H., Liu, Y.-Z., Li, J.-B., Sun, P., Zhao, X.-C., et al. (2009). Photophysical and photocatalytic properties of core-ring structured $\mathrm{NiCo} 2 \mathrm{O} 4$ nanoplatelets. J. Phys. Chem. C 113, 14083-14087. doi:10.1021/jp900028t

Huang, L., Chen, D. C., Ding, Y., Feng, S., Wang, Z. L., and Liu, M. L. (2013). Nickelcobalt hydroxide nanosheets coated on $\mathrm{NiCo} 2 \mathrm{O} 4$ nanowires grown on carbon fiber paper for high-performance pseudocapacitors. Nano Lett. 13, 3135-3139. doi:10.1021/Nl401086t

Huang, X., Qi, X. Y., Boey, F., and Zhang, H. (2012). Graphene-based composites. Chem. Soc. Rev. 41, 666-686. doi:10.1039/C1cs15078b

Jiang, H., Ma, J., and Li, C. Z. (2012). Hierarchical porous NiCo2O4 nanowires for high-rate supercapacitors. Chem. Commun. 48, 4465-4467. doi:10.1039/ C2cc31418e

Kotz, R., Hahn, M., and Gallay, R. (2006). Temperature behavior and impedance fundamentals of supercapacitors. J. Power Sources 154, 550-555. doi:10.1016/j. jpowsour.2005.10.048

Liu, C., Yu, Z., Neff, D., Zhamu, A., and Jang, B. Z. (2010). Graphene-based supercapacitor with an ultrahigh energy density. Nano Lett. 10, 4863-4868. doi:10.1021/nl102661q

Liu, M. C., Kong, L. B., Lu, C., Li, X. M., Luo, Y. C., and Kang, L. (2012). A sol-gel process for fabrication of $\mathrm{NiO} / \mathrm{NiCo} 2 \mathrm{O} 4 / \mathrm{Co} 3 \mathrm{O} 4$ composite with improved electrochemical behavior for electrochemical capacitors. ACS Appl. Mater. Interfaces 4, 4631-4636. doi:10.1021/Am301010u

Liu, X. R., and Pickup, P. G. (2008). Performance and low temperature behaviour of hydrous ruthenium oxide supercapacitors with improved power densities. Energy Environ. Sci. 1, 494-500. doi:10.1039/B809939a

Liu, X. Y., Shi, S. J., Xiong, Q. Q., Li, L., Zhang, Y. J., Tang, H., et al. (2013). Hierarchical NiCo2O4@NiCo2O4 core/shell nanoflake arrays as high-performance supercapacitor materials. ACS Appl. Mater. Interfaces 5, 8790-8795. doi:10.1021/ Am $402681 \mathrm{~m}$

Luo, J.-M., Gao, B., and Zhang, X.-G. (2008). High capacitive performance of nanostructured $\mathrm{Mn}-\mathrm{Ni}-\mathrm{Co}$ oxide composites for supercapacitor. Mater. Res. Bull. 43, 1119-1125. doi:10.1016/j.materresbull.2007.06.006

Masarapu, C., Zeng, H. F., Hung, K. H., and Wei, B. Q. (2009). Effect of temperature on the capacitance of carbon nanotube supercapacitors. ACS Nano 3, 2199-2206. doi:10.1021/Nn900500n

See, D. M., and White, R. E. (1997). Temperature and concentration dependence of the specific conductivity of concentrated solutions of potassium hydroxide. J. Chem. Eng. Data 42, 1266-1268. doi:10.1021/je970140x

Shen, L. F., Che, Q., Li, H. S., and Zhang, X. G. (2014). Mesoporous NiCo2O4 nanowire arrays grown on carbon textiles as binder-free flexible electrodes for energy storage. Adv. Funct. Mater. 24, 2630-2637. doi:10.1002/adfm.201303138

Simon, P., and Gogotsi, Y. (2008). Materials for electrochemical capacitors. Nat. Mater. 7, 845-854. doi:10.1038/Nmat2297

Simon, P., Gogotsi, Y., and Dunn, B. (2014). Where do batteries end and supercapacitors begin? Sci. Mag. 343, 1210-1211. doi:10.1126/science.1249625

Wang, H. W., and Wang, X. F. (2013). Growing nickel cobaltite nanowires and nanosheets on carbon cloth with different pseudocapacitive performance. ACS Appl. Mater. Interfaces 5, 6255-6260. doi:10.1021/Am4012484

Wang, Q. F., Wang, X. F., Liu, B., Yu, G., Hou, X. J., Chen, D., et al. (2013). NiCo2O4 nanowire arrays supported on $\mathrm{Ni}$ foam for high-performance flexible allsolid-state supercapacitors. J. Mater. Chem. A 1, 2468-2473. doi:10.1039/ C2ta01283a

\section{Supplementary Material}

The Supplementary Material for this article can be found online at http://journal.frontiersin.org/article/10.3389/fenrg.2015.00039

Wei, T. Y., Chen, C. H., Chien, H. C., Lu, S. Y., and Hu, C. C. (2010). A cost-effective supercapacitor material of ultrahigh specific capacitances: spinel nickel cobaltite aerogels from an epoxide-driven sol-gel process. Adv. Mater. Weinheim 22, 347. doi:10.1002/adma.200902175

Wu, Z. B., Zhu, Y. R., and Ji, X. B. (2014). NiCo2O4-based materials for electrochemical supercapacitors. J. Mater. Chem. A 2, 14759-14772. doi:10.1039/C4ta02390k

Xiong, G., Kundu, A., and Fisher, T. S. (2015a). Thermal Effects in Supercapacitors. Switzerland: Springer.

Xiong, G., Kundu, A., and Fisher, T. S. (2015b). "Thermal management in electrochemical energy storage systems," in Thermal Effects in Supercapacitors, ed. F. A. Kulacki (Switzerland: Springer), 1-10.

Xiong, G. P., Hembram, K. P. S. S., Reifenberger, R. G., and Fisher, T. S. (2013). $\mathrm{MnO}_{2}$-coated graphitic petals for supercapacitor electrodes. J. Power Sources 227, 254-259. doi:10.1016/j.jpowsour.2012.11.040

Xiong, G. P., Meng, C. Z., Reifenberger, R. G., Irazoqui, P. P., and Fisher, T. S. (2014a). Graphitic petal electrodes for all-solid-state flexible supercapacitors. Adv. Energy Mater. 4, 1300515. doi:10.1002/Aenm.201300515

Xiong, G. P., Meng, C. Z., Reifenberger, R. G., Irazoqui, P. P., and Fisher, T. S. (2014b). A review of graphene-based electrochemical microsupercapacitors. Electroanalysis 26, 30-51. doi:10.1002/elan.201300238

Xu, X., Zhou, H., Ding, S. J., Li, J., Li, B. B., and Yu, D. M. (2014). The facile synthesis of hierarchical $\mathrm{NiCoO} 2$ nanotubes comprised ultrathin nanosheets for supercapacitors. J. Power Sources 267, 641-647. doi:10.1016/j.jpowsour.2014.05.077

Yu, L., Zhang, G. Q., Yuan, C. Z., and Lou, X. W. (2013). Hierarchical $\mathrm{NiCo} 2 \mathrm{O} 4 @ \mathrm{MnO} 2$ core-shell heterostructured nanowire arrays on Ni foam as high-performance supercapacitor electrodes. Chem. Commun. 49, 137-139. doi: $10.1039 / \mathrm{C} 2 \mathrm{cc} 37117 \mathrm{k}$

Yuan, C., Li, J., Hou, L., Zhang, X., Shen, L., and Lou, X. W. D. (2012a). Ultrathin mesoporous $\mathrm{NiCo} 2 \mathrm{O} 4$ nanosheets supported on $\mathrm{Ni}$ foam as advanced electrodes for supercapacitors. Adv. Funct. Mater. 22, 4592-4597. doi:10.1002/adfm. 201200994

Yuan, C. Z., Li, J. Y., Hou, L. R., Zhang, X. G., Shen, L. F., and Lou, X. W. (2012b). Ultrathin mesoporous $\mathrm{NiCo} 2 \mathrm{O} 4$ nanosheets supported on $\mathrm{Ni}$ foam as advanced electrodes for supercapacitors. Adv. Funct. Mater. 22, 4592-4597. doi:10.1002/ adfm.201200994

Zhang, G. Q., and Lou, X. W. (2013a). Controlled growth of NiCo2O4 nanorods and ultrathin nanosheets on carbon nanofibers for high-performance supercapacitors. Sci. Rep. 3, 1-6. doi:10.1038/Srep01470

Zhang, G. Q., and Lou, X. W. (2013b). General solution growth of mesoporous $\mathrm{NiCo} 2 \mathrm{O} 4$ nanosheets on various conductive substrates as high-performance electrodes for supercapacitors. Adv. Mater. Weinheim 25, 976-979. doi:10.1002/ adma.201204128

Zhang, G. Q., Wu, H. B., Hoster, H. E., Chan-Park, M. B., and Lou, X. W. (2012). Single-crystalline $\mathrm{NiCo} 2 \mathrm{O} 4$ nanoneedle arrays grown on conductive substrates as binder-free electrodes for high-performance supercapacitors. Energy Environ. Sci. 5, 9453-9456. doi:10.1039/C2ee22572g

Zheng, J. P., and Jow, T. R. (1996). High energy and high power density electrochemical capacitors. J. Power Sources 62, 155-159. doi:10.1016/S0378-7753(96) 02424-X

Zou, R. J., Xu, K. B., Wang, T., He, G. J., Liu, Q., Liu, X. J., et al. (2013). Chain-like NiCo2O4 nanowires with different exposed reactive planes for highperformance supercapacitors. J. Mater. Chem. A 1, 8560-8566. doi:10.1039/ C3ta11361b

Conflict of Interest Statement: The authors declare that the research was conducted in the absence of any commercial or financial relationships that could be construed as a potential conflict of interest.

Copyright (c) 2015 Xiong, He, Liu, Chen and Fisher. This is an open-access article distributed under the terms of the Creative Commons Attribution License (CC BY). The use, distribution or reproduction in other forums is permitted, provided the original author(s) or licensor are credited and that the original publication in this journal is cited, in accordance with accepted academic practice. No use, distribution or reproduction is permitted which does not comply with these terms. 